\title{
Predictive factors for adenoma detection rates: a video study of endoscopist practices
}

\section{(ㄷ)(1) $\odot$}

Authors

Sun Young Yang ${ }^{1}$, Susan Y. Quan ${ }^{2,3}$, Shai Friedland ${ }^{2,3}$, Jennifer Y. Pan ${ }^{2,3}$

Institutions

1 Division of Gastroenterology, Seoul National University Hospital Healthcare System Gangnam Center, Seoul, Republic of Korea

2 Veterans Affairs Palo Alto Health Care System, Palo Alto, California, United States

3 Division of Gastroenterology \& Hepatology, Stanford University School of Medicine, Palo Alto, California, United States

submitted 23.6.2020

accepted after revision 19.10 .2020

Bibliography

Endoscopy International Open 2021; 09: E216-E223

DOI 10.1055/a-1321-0990

ISSN 2364-3722

(c) 2021. The Author(s).

This is an open access article published by Thieme under the terms of the Creative Commons Attribution-NonDerivative-NonCommercial License, permitting copying and reproduction so long as the original work is given appropriate credit. Contents may not be used for commecial purposes, or adapted, remixed, transformed or built upon. (https://creativecommons.org/licenses/by-nc-nd/4.0/)

Georg Thieme Verlag KG, Rüdigerstraße 14,

70469 Stuttgart, Germany

Corresponding author

Jennifer Pan, 3801 Miranda Ave., Suite GI-111, Palo Alto, CA 94304, USA

Fax: +1-888-341-2787

jenpan@stanford.edu

\section{ABSTRACT}

Background and study aims In 2015, the American Society for Gastrointestinal Endoscopy (ASGE) and American College of Gastroenterology (ACG) Task Force on Quality in Endoscopy deemed adenoma detection rate (ADR) the most important quality measure for colonoscopy. There has been much interest in factors that can increase ADR. To date, however, few studies have looked at what intraprocedural endoscopist practices are associated with improving ADR. We conducted a retrospective review of colonoscopy videos to evaluate intra-procedural practices that could be associated with ADR.

Methods Videos were recorded of colonoscopies performed between September and December 2017 at the Palo Alto Veterans Affairs Health Care System. Colonoscopies for screening and surveillance were included for video review. Factors assessed included withdrawal time, intraprocedural cleaning, inspection technique, and other variables (colon distention, removal of equivocal/hyperplastic polyps). A series of multiple regression analyses was conducted on variables of interest before running a final model of significant predictors.

Results A total of 130 videos were reviewed from nine endoscopists whose ADRs ranged between $37.5 \%$ and $73.7 \%$. The final regression model was significant $(F=$ $15.35, \mathrm{df}=2, P=0.0044), R^{2}=0.8365$ ) with close inspection of behind folds and quality of cecal inspection being the factors highly correlated with predicting ADR. Withdrawal and inspection times, colonic wall distention, removal of equivocal/hyperplastic polyps, quality of rectal inspection, suctioning, and washing were factors moderately correlated with predicting ADR.

Conclusions We found that behind-fold inspection and a meticulous cecal inspection technique were predictive of a high ADR.

\section{Introduction}

Colonoscopy plays an integral role in colorectal cancer screening. Colonoscopy can both diagnose and prevent colorectal cancer. Colorectal cancer mortality can be improved through early detection and removal of adenomas, which are precancer- ous lesions. However, the utility of colonoscopy depends on a high-quality examination.

In the updated 2015 American Society for Gastrointestinal Endoscopy (ASGE) and American College of Gastroenterology (ACG) Task Force on Quality in Endoscopy guidelines for colonoscopy, adenoma detection rate (ADR) was considered the 
most important colonoscopy quality measure given the evidence that for every $1 \%$ increase in ADR, an associated $3 \%$ and $5 \%$ reduction was observed in colorectal cancer incidence and mortality, respectively [1]. They also suggested that endoscopists with ADRs $<25 \%$ should take steps to improve their performance, though they did not discuss endoscopist-related practices on how to do so.

High-quality bowel preparation and adequate withdrawal time have been studied extensively as quality measures that help endoscopists improve their ADRs. In a large communitybased practice and observational prospective multicenter quality assurance review, endoscopists with mean withdrawal times $\geq 6$ minutes had higher ADRs [2,3]. Recently, withdrawal time of up to 11 minutes was associated with a higher ADR in the UK [4]. However, there is concern that some endoscopists may "play to the clock" by slowing down withdrawal to meet the 6minute goal while performing low-quality withdrawal inspection. Thus, while the ASGE and ACG Taskforce have recommended withdrawal times $\geq 6$ minutes during colonoscopy, this is considered a "very weak" $(2 \mathrm{C})$ recommendation based on observational studies [5, 6].

Adequate preparation quality has also been shown to be associated with detection of polyps $<9 \mathrm{~mm}$ in diameter, and missed adenomas are frequently detected on repeat colonoscopy in patients with inadequate bowel preparation on initial screening colonoscopy $[7,8]$. Inadequate bowel preparation is commonly thought to lead to lower ADRs, longer insertion and withdrawal times, more repeat colonoscopies, and increased costs $[9,10]$. Conversely, other studies have shown that reported Boston Bowel Preparation Scale (BBPS) scores of the highest levels of bowel cleanliness (8-9) resulted in lower polyp detection rates (PDR) and ADRs than in colonoscopies with fair to good scores (6-7) [11,12]. The authors felt this discrepancy might be related to endoscopists having longer and better visualization of the colonic mucosa while cleaning, and so, encouraged endoscopists to avoid a sense of overconfidence when finding an excellent bowel preparation during the inspection phase. They also cautioned, however, that endoscopists should not sacrifice inspection technique or time spent performing intra-procedural bowel cleansing.

Recently, studies have been conducted on new endoscopic technologies to improve ADR. Narrow-band imaging (NBI), iscan, Intelligent ChromoEndoscopy (Fujinon, Tokyo, Japan), and autofluence imaging can aid endoscopists in detecting and inspecting lesions by differentiating them from the surrounding mucosa [13]. Distal attachment caps, Endocuff Vision (Arc Medical, Leeds, England), EndoRings (US Endoscopy, Mentor, Ohio, United States), Fuse Full Spectrum Endoscopy (EndoChoice, Alpharetta, Georgia, United States), Third Eye Panoramic device (Avantis Medical Systems, San Jose, California, United States) and G-EYE system (Smart Medical Systems, Israel) are reported to help inspection behind folds [14]. However, the cost-effectiveness of these technologies and devices in increasing ADR is still controversial [15].

There has been much interest in variables that can increase ADR, and some experts propose that endoscopist-related variables are still the most important [16]. Technical expertise not only prevents adverse events, but also increases the detection of colorectal adenomas $[17,18]$. Our pilot study sought to evaluate different intra-procedural withdrawal practices and techniques in order to determine which variables are most associated with a higher ADR and to potentially create a new technique metric that can be more easily measured and tracked for reporting and quality improvement.

\section{Methods}

\section{Study design}

We conducted a retrospective review of colonoscopy withdrawal videos. We developed a novel scoring system based on variables that were previously studied in association with colonoscopy technique and ADR, with further definition of broad categories described. Additional variables of interest based on the authors' combined clinical experience and newer imaging technology were also considered for evaluation and comparison $[17,18]$. Final variables chosen included withdrawal time (inspection time excluding polypectomy time, cecum inspection time), intra-procedural cleaning (washing, suctioning, change in BBPS score), inspection technique (inspection behind folds, quality of cecal inspection, quality of rectal inspection - both forward and retroflexed views, attention to minimally abnormal areas of mucosa, narrow band imaging [NBI] use), and other variables (colon distention, removal of equivocal/hyperplastic polyps).

For purposes of statistical analysis, the prior 7-point scale created by Rex et al was simplified to a three-category score: 0,1 , or 2 points for each variable ( Table 1 ) [17]. The score of cleaning, inspection technique, and distention, was summed from three segments: right colon (cecum, ascending colon, and hepatic flexure), transverse colon, and left colon (splenic flexure, descending colon, sigmoid colon, and rectum). Inspection behind folds was rated as 0 when performed $<50 \%$ of the time, 1 when performed between 50 and $75 \%$ of the time, and 2 when performed $>75 \%$ of the time. Cecal inspection quality was rated as 0 when the inspection was cursory, 1 when average, and 2 when meticulous. The Stanford University Institutional Review Board approved the study protocol.

\section{Outcomes and aims}

The outcome of interest in our study was the historical ADR of our endoscopists. A retrospective review of average-risk screening colonoscopies performed by endoscopists over the preceding 6 months was conducted to calculate historical ADRs for each endoscopist. Our primary aim was to review the association of certain endoscopic practices with ADR. Our secondary aim was to identify the practices that best correlated with ADR and create a potential predictive model.

\section{Inclusion and exclusion criteria}

Colonoscopies performed for indications of screening or surveillance were considered eligible for video review. Therefore, this only included patients aged 50 to 84 years old. Colonoscopies indicated for high-risk screening or surveillance (including for patients with inflammatory bowel disease [IBD] and perso- 
- Table 1 Variables of interest and scoring system.

\begin{tabular}{|c|c|c|c|}
\hline Variable & \multicolumn{3}{|l|}{ Scoring system ${ }^{1}$} \\
\hline \multicolumn{4}{|l|}{ Withdrawal time } \\
\hline - Withdrawal time (total) & \multirow{2}{*}{\multicolumn{2}{|c|}{ Minutes }} & \\
\hline $\begin{array}{l}\text { - Inspection time (excluding } \\
\text { interventions) }\end{array}$ & & & \\
\hline Cleaning & 0 & 1 & 2 \\
\hline - Washing of mucosa ${ }^{1}$ & $\begin{array}{l}\text { Very little } \\
(<50 \% \text { residual stool cleaned) }\end{array}$ & $\begin{array}{l}\text { Average } \\
\text { ( } 50 \%-75 \% \text { residual stool } \\
\text { cleaned) }\end{array}$ & $\begin{array}{l}\text { Meticulous washing } \\
\text { (>75\% cleaned) }\end{array}$ \\
\hline - Suctioning of puddles ${ }^{1}$ & $\begin{array}{l}\text { Leaving large puddles behind } \\
\text { (<50\% mucosa seen) }\end{array}$ & $\begin{array}{l}\text { Average } \\
\text { (50\%-75\% mucosa seen) }\end{array}$ & $\begin{array}{l}\text { Meticulous puddle suctioning } \\
\text { (>75\% mucosa seen) }\end{array}$ \\
\hline - Prep Quality ${ }^{1}$ & \multirow{4}{*}{\multicolumn{2}{|c|}{ Score }} & \\
\hline - Pre-clean BBPS & & & \\
\hline - Post-clean BBPS & & & \\
\hline - Change in BBPS & & & \\
\hline Inspection & 0 & 1 & 2 \\
\hline - Behind folds ${ }^{1}$ & $\begin{array}{l}\text { Very little } \\
(<50 \%)\end{array}$ & $\begin{array}{l}\text { Average } \\
(50 \%-75 \%)\end{array}$ & $\begin{array}{l}\text { Consistently reinsert to look behind } \\
\text { each fold } \\
(>75 \%)\end{array}$ \\
\hline - Minimally abnormal areas² & Never & $\begin{array}{l}\text { Sometimes } \\
(50 \%-75 \%)\end{array}$ & $\begin{array}{l}\text { Often } \\
(>75 \%)\end{array}$ \\
\hline - Use of narrow-band imaging & Never & $\begin{array}{l}\text { Occasionally } \\
(50 \%-75 \%)\end{array}$ & $\begin{array}{l}\text { Often } \\
(>75 \%)\end{array}$ \\
\hline - Cecum & Not well visualized & Average & Careful inspection \\
\hline \multicolumn{4}{|l|}{ - Rectum } \\
\hline - Forward view & Quick pass & Average & Multiple passes with careful inspection \\
\hline - Retroflexion & None & Quick view & Full view with rotation \\
\hline Others & 0 & 1 & 2 \\
\hline - Distention ${ }^{1}$ & $\begin{array}{l}\text { Many areas incompletely } \\
\text { distended } \\
(<50 \%)\end{array}$ & $\begin{array}{l}\text { Usually } \\
(50 \%-75 \%)\end{array}$ & $\begin{array}{l}\text { Always } \\
(>75 \%)\end{array}$ \\
\hline $\begin{array}{l}\text { - Equivocal/hyperplastic polyp } \\
\text { removal }^{2}\end{array}$ & $\begin{array}{l}\text { Never/Rarely } \\
(<50 \%)\end{array}$ & $\begin{array}{l}\text { Occasionally } \\
(50 \%-75 \%)\end{array}$ & $\begin{array}{l}\text { Often } \\
(>75 \%)\end{array}$ \\
\hline $\begin{array}{l}\text { BBPS, Boston Bowel Prep Score. } \\
{ }^{1} \text { Per segment (if applicable). } \\
2 \text { If present. }\end{array}$ & & & \\
\hline
\end{tabular}

nal or family history of colorectal cancer [CRC]), or for diagnostic purposes (such as gastrointestinal bleeding, abnormal radiologic findings, follow-up of diverticulitis) were also excluded.

Videos from colonoscopies in which the mucosal examination was incomplete (due to inadequate post-cleaning preparation quality or patient intolerance) were excluded. In addition, we excluded colonoscopies involving trainees or endoscopists who did not have a sufficient number of videos for review $(n<5)$ or recent ADR data available.

\section{Video recording and review}

All colonoscopy withdrawals between September and December 2017 at the Palo Alto Veterans Affairs Health Care System were prospectively recorded. All participating endoscopists consented to video recording with the understanding that they would be used for quality improvement purposes. Endoscopists were not told of final variable selection or the scoring system to be used to prevent selective practice change. They were encouraged to perform colonoscopy as they normally would. Endoscopy nurses were instructed to begin the video recording once the endoscopist reported reaching the cecum (as 
defined by visualization of the appendiceal orifice and/or ileocecal valve). Reporting of cecum time is part of our standard documentation, and so, did not have any effect on the endoscopist's knowledge of whether a specific colonoscopy would be recorded or reviewed

While colonoscopy videos from three of the four study authors (JP, SQ, and SF) were included in the study, videos were selected at random for review for each endoscopist, and endoscopists did not know which videos would be selected. In addition, there were no changes in scheduled patient volume or allotted procedure times for any endoscopists during the study period to minimize practice changes. For consistency, the primary video review and scoring of all included colonoscopy videos was performed by one independent, blinded gastroenterologist with extensive endoscopic experience (SY) who did not have videos included in the study.

\section{Statistics and model design}

The relationship between ADR and variables of interest was assessed using descriptive statistics with SAS 9.4 (Cary, NC). R ${ }^{2}$ was calculated, and a threshold for statistical significance was set at $R^{2}>0.6$. We selected variables found to be significant in univariable analysis for use as predictors in the multivariable model.

Individual variables were analyzed for relation to ADR, with linear association determined by calculating $\mathrm{R}^{2}$. A series of multiple regression analyses were conducted on variables of interest before running a final model of significant predictors for ADR.

\section{Results}

\section{Study population}

The Veterans Affairs Palo Alto Health Care System (VAPAHCS) cares for over 67,000 enrolled veterans. The uptake of age-appropriate colorectal cancer screening (using either stool Fecal Immunochemical Test [FIT] or colonoscopy, per patient preference) in our system is $83 \%$. Annually, endoscopists of the section of Gastroenterology and Hepatology perform approximately 3,500 colonoscopies for different indications, with the majority (approximately two-thirds) performed for screening and surveillance. All endoscopists in our study are board-certified skilled specialists with varying lengths of experience in performing colonoscopies, but who each perform at least 200 colonoscopies annually. Historical ADRs for our endoscopists ranged from $37.5 \%$ to $73.7 \%$ ( $\downarrow$ Table 2 ). The mean age of patients was 65 years old, with $95 \%$ being male.

\section{Patient and video demographics}

Between the study dates of September and December 2017, 291 total colonoscopy withdrawal videos were captured ( $\triangleright$ Fig. 1). Of these, 36 videos were excluded due to procedure indication or patient age, while 44 videos were excluded due to video quality, recording issues, or the presence of a trainee during the colonoscopy. An additional six videos from five endoscopists with insufficient videos $(n<5)$ or historical ADR info, as well as 18 videos with inadequate prep quality were excluded.
- Table2 Demographics of providers and ADR.

\begin{tabular}{|c|l|l|l|}
\hline $\begin{array}{l}\text { Endos- } \\
\text { copist }\end{array}$ & $\begin{array}{l}\text { Historical } \\
\text { ADR }\end{array}$ & $\begin{array}{l}\text { Number of videos re- } \\
\text { viewed and included }\end{array}$ & $\begin{array}{l}\text { Age of } \\
\text { patient } \\
\text { mean (SD) }\end{array}$ \\
\hline 1 & $63.2 \%$ & 15 & $67.3(6.5)$ \\
\hline 2 & $53.7 \%$ & 15 & $63.6(7.7)$ \\
\hline 3 & $73.7 \%$ & 14 & $67.9(7.8)$ \\
\hline 4 & $64.8 \%$ & 17 & $64.3(5.8)$ \\
\hline 5 & $57.8 \%$ & 16 & $64.0(7.9)$ \\
\hline 6 & $41.2 \%$ & 14 & $64.7(5.8)$ \\
\hline 9 & $54.5 \%$ & 16 & $65.3(7.0)$ \\
\hline 10 & $39.7 \%$ & 14 & $66.6(10.0)$ \\
\hline 12 & $37.5 \%$ & 9 & $69.3(7.0)$ \\
\hline
\end{tabular}

$A D R$, adenoma detection rate; SD, standard deviation.

\section{1 videos captured}

\begin{tabular}{|c|c|c|}
\hline $\begin{array}{l}44 \text { excluded due to: } \\
\text { - Video quality } \\
\text { - Technical errors } \\
\text { - Presence of } \\
\text { trainee }\end{array}$ & $\leftarrow$ & $\begin{array}{l}36 \text { excluded due to: } \\
\text { - High-risk screening/ } \\
\text { surveillance (IBD, } \\
\text { personal or family } \\
\text { history of CRC) }\end{array}$ \\
\hline $\begin{array}{l}6 \text { videos } \\
\text { (5 endoscopists) } \\
\text { excluded due to: } \\
\text { - Insufficient ADR } \\
\text { data }\end{array}$ & $\leftarrow$ & $\begin{array}{l}\text { (bleeding, radiologic } \\
\text { findings, diverticulitis } \\
\text { follow-up, etc.) } \\
\text { - Age }<50 \text { or }>84 \text { years old }\end{array}$ \\
\hline $\begin{array}{l}\text { - Insufficient } \\
\text { number of } \\
\text { videos }(n<5)\end{array}$ & $\rightarrow$ & $\begin{array}{l}18 \text { excluded due to: } \\
\text { - Inadequate prep } \\
\text { post-cleaning (by BBPS) }\end{array}$ \\
\hline \multicolumn{3}{|c|}{187 eligible videos (9 endoscopists) } \\
\hline \multicolumn{3}{|c|}{$\begin{array}{l}2 / 3 \text { of videos per endoscopist randomly selected } \\
\text { for review }\end{array}$} \\
\hline & $\downarrow$ & \\
\hline $\begin{array}{l}130 \text { total } \\
\text { reviewed }\end{array}$ & $\begin{array}{l}\text { videos } \\
\text { and inc }\end{array}$ & $\begin{array}{l}\text { ( } 9 \text { endoscopists) } \\
\text { luded for analysis }\end{array}$ \\
\hline
\end{tabular}

Fig. 1 Video demographics.

Of the remaining 187 eligible videos, 130 randomly-selected videos representing two-thirds of those from each of the nine remaining endoscopists were chosen for review, scoring, and inclusion in our model. 


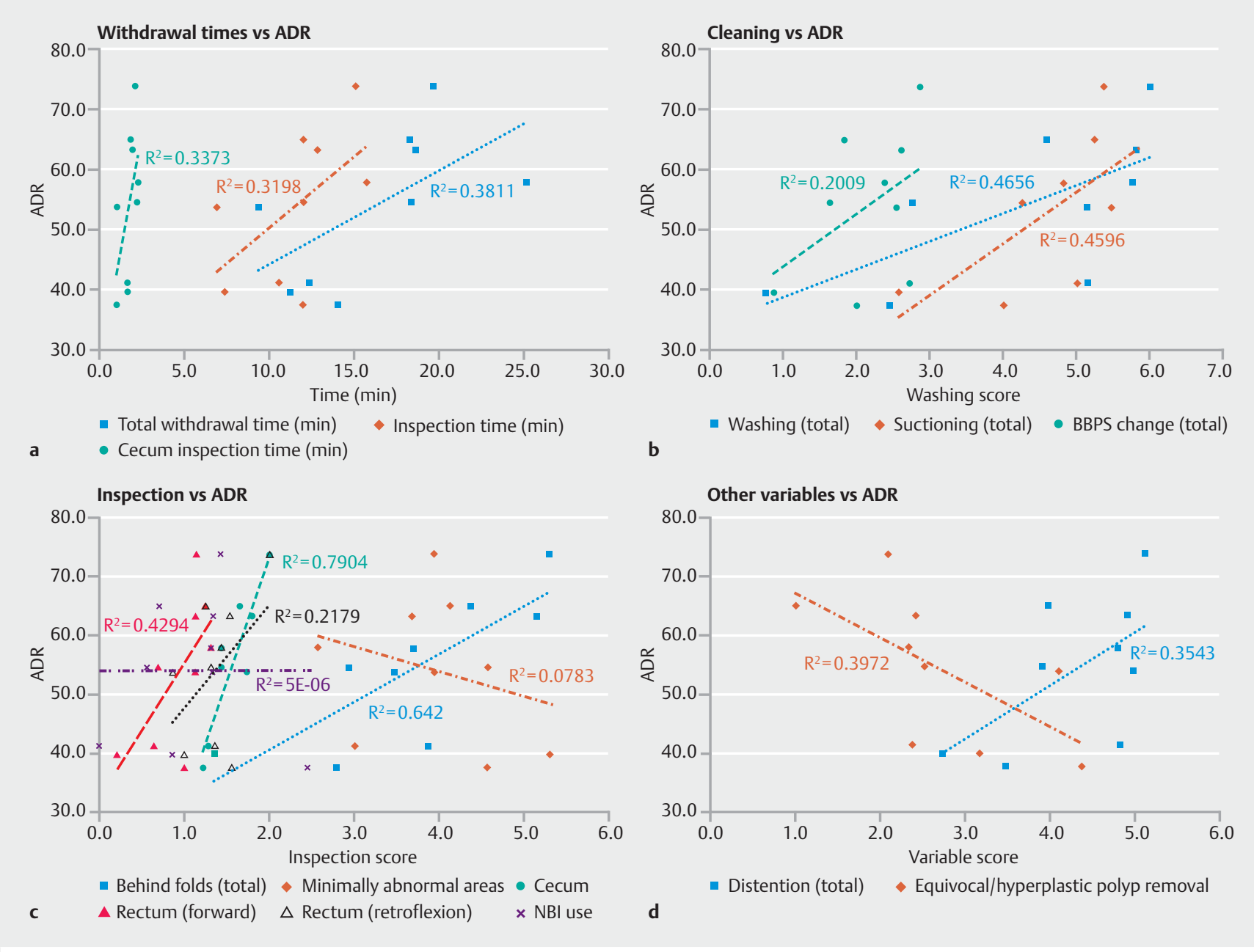

- Fig. 2 Linear regression of individual variables vs ADR. a Withdrawal times. b Cleaning technique. c Inspection technique. d Other.

\section{Correlations between individual variables and ADR}

Linear regression of the individual variables as correlated with $A D R$ is shown in $>$ Fig. 2 . The variables found to have the lowest correlations were noted to be NBI use $\left(R^{2}=0.000005\right)$, inspection of minimally abnormal areas $\left(R^{2}=0.0783\right)$, change in BBPS score after cleaning $\left(R^{2}=0.2009\right)$, and retroflexed inspection of the rectum $\left(R^{2}=0.2179\right)$. Variables with moderate degree of correlation included withdrawal and inspection times $\left(R^{2}=\right.$ $0.3198-0.3811)$, colonic wall distention $\left(R^{2}=0.3543\right)$, removal of equivocal/hyperplastic polyps $\left(R^{2}=0.3972\right)$, forward view inspection of the rectum $\left(R^{2}=0.4294\right)$, suctioning $\left(R^{2}=0.4596\right)$, and washing $\left(R^{2}=0.4656\right)$. The variables with the highest degree of correlation with ADR were careful inspection behind colonic mucosal folds $\left(R^{2}=0.642\right)$ and of the cecum $\left(R^{2}=0.7904\right)$.

\section{Final regression model}

We used stepwise regression for selection of variables to include as predictors in the final model for ADR. The final regression model included close inspection behind mucosal folds and of the cecum. This model was significant $(F=15.35, \mathrm{df}=2, P=$ 0.0044), $R^{2}=0.8365$, when compared to actual ADR ( $>$ Fig. $\mathbf{3}$ ).

\section{Discussion}

Our study builds upon the work of two main prior video studies that have evaluated the relationship between withdrawal technique and detection of colorectal adenomas $[17,18]$. In Rex's study, four experts observed and scored four withdrawal variables (fold examination, cleaning and suctioning, distention, and withdrawal time) of two endoscopists with adenoma miss rates of $17 \%$ and $48 \%$, respectively. They reported that the aggregate withdrawal technique score was higher in the endoscopist with a lower adenoma miss rate. Using a different scoring scale but also evaluating these same variables, Lee et al divided 11 endoscopists into tertiles based on their ADRs and also found that withdrawal technique is an important indicator in determining ADRs.

In addition to withdrawal and inspection time, we further defined and subdivided withdrawal technique variables, as well as simplified the scoring system to better characterize the specific practices of endoscopists in our institution. Due to 


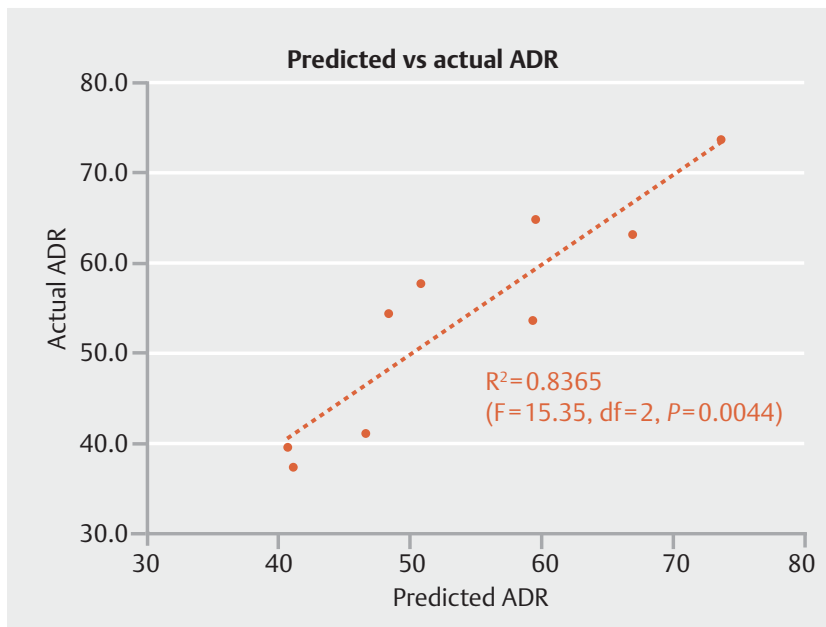

Fig. 3 Final regression model, including behind fold and cecal inspection.

higher historical ADRs noted in our institution, in which no endoscopist could be considered as having a "low" ADR, we opted to evaluate the association of these individual variables with ADR as a continuous outcome, rather than a binary or categorical variable.

Among the withdrawal techniques we evaluated, we found careful inspection to be the most important factor associated with ADR - specifically, behind-fold $\left(R^{2}=0.642\right)$ and cecum $\left(R^{2}\right.$ $=0.7904$ ) inspection. In a study analyzing the location of missed adenomas by comparing the results of optical colonoscopy and those of virtual colonoscopy, most of the missed adenomas were found on the proximal side of the folds [19]. Our findings correlate with their recommendation that more meticulous maneuvers should be used to closely evaluate the mucosa behind folds during withdrawal. Recent studies of assistive devices such as caps, EndoCuff, and EndoRings have found that these can improve ADR by helping the endoscopist better visualize and inspect behind-fold colonic mucosa [14].

Interestingly, in our study, cecum inspection technique also had a high individual correlation with ADR, separate from behind-fold inspection, which correlates with recent recognition that many subtle and missed lesions tend to arise from the cecum and right colon. In contrast to the distal colon, the number of missed adenomas as well as the recurrence of adenomas and advanced adenomas in the proximal colon are high [20]. This may explain why, while colonoscopy is overall found to lower the incidence and mortality of colorectal cancer, this effect has not been seen in proximal colon cancers [21]. Careful inspection of the cecum and right colon may play a major role in improving ADR.

Similar to Lee et al, we found only a modest correlation $\left(R^{2}=\right.$ 0.3811 ) between mean withdrawal time and ADR, though our overall mean withdrawal times were longer than those of their study. Lee et al proposed that inspection time [22] - defined as the time in which the colonoscope is actively moving and the endoscopist is actively examining the colon - might be more associated with ADR; however, we did not find any significant correlation $\left(R^{2}=0.3198\right)$. In addition, we found that while cecum inspection technique was associated with a better ADR, cecum inspection time had only a moderate correlation $\left(R^{2}=\right.$ 0.3373 ). Studies have found that longer colonoscopy withdrawal times yield higher PDRs, while shorter mean colonoscopy withdrawal times are independently associated with lower ADRs and increased risk of CRC $[23,24]$. However, quality improvement studies have found that mandatory minimum withdrawal times without emphasis on withdrawal technique do not result in improved PDRs [25]. Therefore, withdrawal times (including inspection and cecum inspection times) cannot be considered surrogates for determination of mucosal inspection quality.

Close evaluation of minimally abnormal areas and removal/ sampling of equivocal or hyperplastic-appearing polyps were found to have only low-to-moderate correlation with ADR, and likely contributed to longer withdrawal times without necessarily improving inspection quality. This suggests that more education may be helpful in increasing endoscopist confidence in differentiating precancerous neoplastic lesions from benign lesions that do not need to be removed to improve cost-effectiveness of colonoscopy screening. While Saligram et al suggest that the use of tools like narrow-band imaging (NBI) may help train gastroenterologists in identifying polyp histology [26], our study found that the use of NBI during mucosal inspection was not correlated with ADR. There is significant growing interest in the use of machine learning for intra-procedural detection and classification of neoplastic lesions, though the cost-effectiveness of such technology has not yet been determined [27].

Hanson et al noted the utility of retroflexion in identifying additional lesions in the anorectum and increasing the adenoma pick-up rate of $8 \%$ to $12 \%$ in screening flexible sigmoidoscopies compared to forward-view examination alone [28] We did not, however, find a significant correlation between the practice of retroflexion $\left(R^{2}=0.2179\right)$ and ADR as compared to forward inspection of the rectum $\left(R^{2}=0.4294\right)$. This may be due to the fact that retroflexion is now a commonly-accepted practice engaged in by all of our endoscopists, with varying degrees of rotation and inspection in the retroflexed view.

We also sought to evaluate the effects of colonic distention on ADR. In our study, colonic distention with $\mathrm{CO}_{2}$ was found to have only moderate correlation with ADR, which is in concordance with the findings of Ball et al [29]. This is likely because improved visualization as a result of luminal distention does not guarantee identification of additional polyps, and many polyps are visible regardless of the degree of distention. Despite this, however, the authors advocate adequate luminal distention as a goal of colonoscope withdrawal as well as dynamic patient position changes during colonoscope withdrawal to mobilize fluid and gas. This technique, although not evaluated in our study, may be beneficial in improving detection of rightsided polyps beyond that of the effect of luminal distention alone. We did not evaluate the use of water distention as opposed to air insufflation on ADR, but other studies have found water exchange, chromoendoscopy with water exchange, or 
total water colonoscopy - while taking longer to perform - do not improve ADR over standard air or $\mathrm{CO}_{2}$ insufflation [30, 31].

Finally, we sought to better characterize cleaning techniques and investigate whether a quantifiable score for cleaning action had an effect on ADR. We evaluated endoscopist practice in washing the mucosa and suctioning large puddles, and also calculated pre- and post-cleaning BBPS scores by segment to see if changes in BBPS achieved through cleaning correlated with $A D R$. We found that while washing and suctioning had moderate associations with ADR, change in BBPS score had low correlation. This suggests that extra effort expenditure on cleaning sufficient to change BBPS intra-procedure may not be cost- or time-effective, and that focusing on improving the preprocedural bowel prep quality of the patients (such as using split-dose preparations) may be more beneficial $[32,33]$.

There are some notable limitations to our study. First, this was a single-center VA study in which the number of female patients in our patient population was only $5 \%$. However, our reviewer was blinded to patient gender, and in general, we did not feel that gender would significantly affect endoscopists' colonoscopy withdrawal practices. In addition, given the small total number of videos and endoscopists, this limited our ability to incorporate more predictor variables into our final predictive model due to the risk of overfitting. Our study, however, is the largest comprehensive video study to date to look at multiple specific withdrawal techniques. We also acknowledge the likelihood of the Hawthorne effect, in which participants modify behavior in response to being studied. As noted by Rex et al [22], the act of video recording itself results in higher-quality technique scores and colonoscopy withdrawal times. While we sought to counteract this effect by blinding the participating endoscopists to which specific techniques and/or variables were being evaluated, randomizing the videos selected for review, and not including the primary reviewer in video recording, we realize this likely does not fully negate the Hawthorne effect. We also note while there is a risk for potential selection bias with the videos of three study authors being included for review, we minimized this by having the randomized selection of videos and scores used for analysis all performed by one author (SY), who did not have any videos in the study.

A strength of our study includes the specificity with which we identified and analyzed different withdrawal techniques, as well as the simplification of our scoring system for improved reproducibility in future studies. While our ADRs (range $37.5 \%-$ $73.7 \%$ ) were relatively high compared to that of the averagerisk population, this is in line with several studies that have found higher adenoma prevalence in the Veteran population $[34,35]$. Because we did not have any endoscopists who met criteria for "low" ADRs (20\% in women, $30 \%$ in men) as defined by the American Society for Gastrointestinal Endoscopy and American College of Gastroenterology Task Force, we were able to focus our results on looking for positive correlative withdrawal techniques, rather than stratifying our endoscopists by ADR on a binary or categorical basis.

Colonoscopy remains gastroenterologists' primary modality for colorectal cancer screening and surveillance because of its ability to prevent colorectal cancer and improve colorectal can- cer mortality through early detection. However, the benefit of colonoscopy is only present when patients receive higher-quality examinations as defined at this time by a higher endoscopist ADR. Our study emphasizes the importance of the withdrawal technique as a factor in endoscopists' ADR with careful inspection of behind-fold mucosa and the cecum being the most important factors. As we focus much of trainee education on efficient and safe insertions, there is less guidance and teaching provided in what aspects of withdrawal techniques are most associated with a high-quality examination.

\section{Conclusion}

Improving ADR should be considered a priority for all endoscopists who perform colonoscopy, and there are multiple ways in which that can be done. Our study focuses on the techniques that endoscopists can change in their own individual practices. Additional data will be needed to strengthen the model, and future efforts will involve validating this model in larger prospective multicenter studies.

\section{Competing interests}

Dr Friedland is a consultant for CapsoVision. The other authors declare that no conflicts of interest exist.

References

[1] Corley DA, Jensen CD, Marks AR et al. Adenoma detection rate and risk of colorectal cancer and death. N Engl J Med 2014; 370: 12981306

[2] Barclay RL, Vicari J], Doughty AS et al. Colonoscopic withdrawal times and adenoma detection during screening colonoscopy. N Engl J Med 2006; 355: 2533-2541

[3] Overholt BF, Brooks-Belli L, Grace M et al. Withdrawal times and associated factors in colonoscopy: a quality assurance multicenter assessment. J Clin Gastroenterol 2010; 44: e80-e86

[4] Lee T], Blanks RG, Rees C] et al. Longer mean colonoscopy withdrawal time is associated with increased adenoma detection: evidence from the Bowel Cancer Screening Programme in England. Endoscopy 2013; 45: $20-26$

[5] Rex DK, Petrini JL, Baron TH et al. Quality indicators for colonoscopy. Am J Gastroenterol 2006; 101: 873-885

[6] Rex DK, Petrini JL, Baron TH et al. Quality indicators for colonoscopy. Gastrointest Endosc 2006; 63: S16-S28

[7] Harewood GC, Sharma VK, de Garmo P. Impact of colonoscopy preparation quality on detection of suspected colonic neoplasia. Gastrointest Endosc 2003; 58: 76-79

[8] Chokshi RV, Hovis CE, Hollander T et al. Prevalence of missed adenomas in patients with inadequate bowel preparation on screening colonoscopy. Gastrointest Endosc 2012; 75: 1197-1203

[9] Froehlich F, Wietlisbach V, Gonvers J] et al. Impact of colonic cleansing on quality and diagnostic yield of colonoscopy: the European Panel of Appropriateness of Gastrointestinal Endoscopy European multicenter study. Gastrointest Endosc 2005; 61: 378-384

[10] Rex DK, Imperiale TF, Latinovich DR et al. Impact of bowel preparation on efficiency and cost of colonoscopy. Am J Gastroenterol 2002; 97: 1696-1700 
[11] Calderwood AH, Thompson KD, Schroy PC et al. Good is better than excellent: bowel preparation quality and adenoma detection rates. Gastrointest Endosc 2015; 81: 691-699.e1

[12] Adike A, Buras MR, Gurudu SR et al. Is the level of cleanliness using segmental Boston bowel preparation scale associated with a higher adenoma detection rate? Ann Gastroenterol 2018; 31: 217-223

[13] Dinesen L, Chua TJ, Kaffes AJ. Meta-analysis of narrow-band imaging versus conventional colonoscopy for adenoma detection. Gastrointest Endosc 2012; 75: 604-611

[14] Rastogi A, Bansal A, Rao DS et al. Higher adenoma detection rates with cap-assisted colonoscopy: a randomised controlled trial. Gut 2012; 61: 402-408

[15] Gupta N. How to improve your adenoma detection rate during colonoscopy. Gastroenterology 2016; 151: 1054-1057

[16] May FP, Shaukat A. State of the science on quality indicators for colonoscopy and how to achieve them. Am J Gastroenterol 2020; 115: 1183-1190

[17] Rex DK. Colonoscopic withdrawal technique is associated with adenoma miss rates. Gastrointest Endosc 2000; 51: 33-36

[18] Lee RH, Tang RS, Muthusamy VR et al. Quality of colonoscopy withdrawal technique and variability in adenoma detection rates (with videos). Gastrointest Endosc 2011; 74: 128-134

[19] Pickhardt PJ, Nugent PA, Mysliwiec PA et al. Location of adenomas missed by optical colonoscopy. Ann Intern Med 2004; 141: 352-359

[20] Brenner H, Chang-Claude J, Seiler CM et al. Protection from colorectal cancer after colonoscopy: a population-based, case-control study. Ann Intern Med 2011; 154: 22-30

[21] Singh H, Nugent Z, Demers AA et al. The reduction in colorectal cancer mortality after colonoscopy varies by site of the cancer. Gastroenterology 2010; 139: 1128-1137

[22] Rex DK, Hewett DG, Raghavendra M et al. The impact of videorecording on the quality of colonoscopy performance: a pilot study. Am J Gastroenterol 2010; 105: 2312-2317

[23] Shaukat A, Rector TS, Church TR et al. Longer withdrawal time is associated with a reduced incidence of interval cancer after screening colonoscopy. Gastroenterology 2015; 149: 952-957
[24] Sanchez W, Harewood GC, Petersen BT. Evaluation of polyp detection in relation to procedure time of screening or surveillance colonoscopy. Am J Gastroenterol 2004; 99: 1941-1945

[25] Sawhney MS, Cury MS, Neeman N et al. Effect of institution-wide policy of colonoscopy withdrawal time $>$ or $=7$ minutes on polyp detection. Gastroenterology 2008; 135: 1892-1898

[26] Saligram S, Rastogi A. Tools for polyp histology prediction. Gastrointest Endosc Clin N Am 2015; 25: 261-286

[27] Vinsard DG, Mori Y, Misawa M et al. Quality assurance of computeraided detection and diagnosis in colonoscopy. Gastrointest Endosc 2019; 90: 55-63

[28] Hanson JM, Atkin WS, Cunliffe WJ et al. Rectal retroflexion: an essential part of lower gastrointestinal endoscopic examination. Dis Colon Rectum 2001; 44: 1706-1708

[29] Ball A], Johal SS, Riley SA. Position change during colonoscope withdrawal increases polyp and adenoma detection in the right but not in the left side of the colon: results of a randomized controlled trial. Gastrointest Endosc 2015; 82: 488-494

[30] Anderson JC, Kahi C], Sullivan A et al. Comparing adenoma and polyp miss rates for total underwater colonoscopy versus standard CO. Gastrointest Endosc 2019; 89: 591-598

[31] Leung JW, Yen AW, Jia H et al. A prospective RCT comparing combined chromoendoscopy with water exchange (CWE) vs water exchange (WE) vs air insufflation (AI) in adenoma detection in screening colonoscopy. United European Gastroenterol J 2019; 7: 477-487

[32] Martel M, Barkun AN, Menard C et al. Split-dose preparations are superior to day-before bowel cleansing regimens: a meta-analysis. Gastroenterology 2015; 149: 79-88

[33] Radaelli F, Paggi S, Hassan C et al. Split-dose preparation for colonoscopy increases adenoma detection rate: a randomised controlled trial in an organised screening programme. Gut 2017; 66: 270-277

[34] Lieberman DA, Weiss DG, Bond JH et al. Use of colonoscopy to screen asymptomatic adults for colorectal cancer. Veterans Affairs Cooperative Study Group 380. N Engl J Med 2000; 343: 162-168

[35] El-Halabi MM, Rex DK, Saito A et al. Defining adenoma detection rate benchmarks in average-risk male veterans. Gastrointest Endosc 2019; 89: 137-143 